\title{
EXPLORING THE ROLES AND CONTRIBUTIONS OF INDUSTRIAL PSYCHOLOGISTS IN SOUTH AFRICA AGAINST A MULTI-DIMENSIONAL CONCEPTUAL FRAMEWORK (PART 2)
}

\author{
GRAEME BARNARD \\ LINDA FOURIE \\ lfourie@uj.ac.za \\ Programme in Industrial Psychology \\ Department of Human Resource Management \\ University of Johannesburg
}

\begin{abstract}
The study was undertaken to explore the professional roles and contributions of industrial psychologists in South Africa. Semi-structured interviews were conducted among 23 registered psychologists to gain their views on the roles and contributions within each of the dimensions of a conceptual framework of organisational success developed earlier. A process of analytical induction, supported by thematic content analysis, revealed a range of generic roles yet specific industrial psychological contributions. The implications of the findings for the development of academic curricula, the establishment of clarity among industrial psychologists and the fostering of awareness in organisations regarding the value of these professionals are discussed.
\end{abstract}

Key words:

Roles of I/O psychology

Industrial and Organisational Psychology (I/O Psychology) as a science had its origins about a century ago when psychologists in the United States of America started to use their insight into human behaviour to address workplace-related problems, such as finding the right person for a job. The discipline has grown and expanded its initial problem-focused approach to embrace a broader domain of interest that currently comprises six widely acknowledged sub-fields: Personnel Psychology, Organisational Psychology, Career Psychology, Consumer Psychology, Ergonomics and Psychometrics. I/O Psychology is an applied science implying that scientific knowledge and the practical application thereof are intimately linked. This relationship between science and practice has come to be known as a scientist/practitioner model (Augustyn, 1982; Muchinsky, 2000; Muchinsky, Kriek \& Schreuder, 2005). The model embodies the notion that the industrial psychologist accumulates, orders and disseminates scientific knowledge and then utilises this knowledge to address work-related problems and challenges. Often new knowledge is created in the process of application thereby strengthening the scientific basis upon which future applications can be based. Human Resource Management (HR), on the other hand, is primarily a management function that is aimed at managing an organisation's human resources in such a way that both the organisation and the individual find benefit (Grobler, W rnich, Carrell, Elbert \& Hatfield, 2002). In South Africa a large degree of fusion and overlap has developed over time relating to the nature and scope of both I/O Psychology and HR.

The confusion is particularly notable in the sub-field of Personnel Psychology. Whilst at an academic level, initially at least, a clear distinction was perceived between the two, current realities suggest differently. This can be attributed to many reasons. Amongst others, the use of the name Personnel Management for courses in I/O Psychology articulated a strong practical and career-orientated image, many qualified industrial psychologists find themselves in HR positions that contribute significantly towards the perceived fusion, and some universities taught I/0 Psychology under the banner of the management sciences, often under the name Personnel Management or later Human Resource Management (Moalusi, 2001; Pienaar \& Roodt, 2001; Schreuder, 1999, 2001; Veldsman, 2001; Venter \& Barkhuizen 2005; Watkins, 2001). This study was not intended to further belabour arguments related to the perceived differences or similarities between the two fields (I/O Psychology and HR). The singular aim of this study was to explore the roles and contributions of industrial psychologists in the workplace, as perceived by professionally registered industrial psychologists themselves.

\section{Social and occupational roles}

The notion of social and occupational roles was perceived to be particularly relevant to this study. The existence of social roles is an important theme in social psychology and concerns the power these exert over individuals. Social roles, social values and social norms are believed necessary in any social system to enhance order and co-existence. Social roles reflect shared expectations about how particular members of a group are supposed to behave; individuals internalise these expectations and direct their behaviour accordingly (Westen, 1998). A key feature of organisations is the existence of organisational or occupational roles. These roles are defined as "the expectations of others about appropriate behavior in a specific position" (Muchinsky, 2003, p. 258). Occupational roles are in essence impersonal and specifically prescribe behaviours for people in a specific job context (Scott, Mitchell \& Birnbaum, 1981). Specific jobs imply inherent values, norms and standards associated with that job that largely guide and inform group members' conduct. Since organisations and their members seemingly have clear expectations in terms of the roles they confer onto individuals within their organisations, it was deemed important to explore the specific roles and contributions of industrial psychologists to facilitate understanding among all stakeholders - the organisation, its members and industrial psychologists themselves.

\section{RESEARCH DESIGN}

In order to overcome the possible limitations of traditional thinking about the roles and contributions of industrial psychologists, now and in the future, the study was designed to approach the question from a different angle. Given the fact that a number of popular business frameworks are widely used in South African to direct and assess organisational activities, it was decided to utilise these frameworks to explore the roles and contributions of industrial psychologists in a discourse familiar to the end-users of industrial psychological services (for example, managers in organisations). If organisations 
use existing business frameworks to direct and monitor their business, it was believed important to frame the roles and contributions of the industrial psychologist in similar terms. For this purpose, three popular business frameworks were identified as a basis for this study: The Balanced Scorecard (Strategic Management Framework) (Kaplan \& Norton, 1996), the South African Excellence Model (Continuous Improvement Framework) (South African Excellence Foundation, 1997) and King II Report on Corporate Governance for South Africa (Institute of Directors, 2002). The three independently developed frameworks were studied in depth to identify similarities, differences and unique contributions within each and these insights were subsequently integrated into a Multi-dimensional Conceptual Framework that was intended to form a basis against which the roles and contributions of industrial psychologists could be 'mirrored' (Barnard \& Fourie, 2007). Table 1 represents a randomly organised presentation of the sixteen dimensions of this framework. This random organising was deliberately done to limit researcher influence on the data gathering and data analysing processes envisaged during the later stages of the research.

TABLE 1

MULTI-DIMENSIONAL CONCEPTUAL FRAMEWORK FOR DEFINING AND DESCRIBING THE ROLES AND CONTRIBUTIONS OF INDUSTRIAL PSYCHOLOGISTS

\begin{tabular}{llll}
\hline $\begin{array}{l}\text { Long-term } \\
\text { Sustainability } \\
\text { of the } \\
\text { Organisation }\end{array}$ & $\begin{array}{l}\text { Governance } \\
\text { and Ethics }\end{array}$ & $\begin{array}{l}\text { Financial } \\
\text { Well-Being } \\
\text { of the } \\
\text { Organisation }\end{array}$ & $\begin{array}{l}\text { Strategic } \\
\text { positioning, } \\
\text { Vision and } \\
\text { Mission }\end{array}$ \\
\hline Strategies & $\begin{array}{l}\text { Organisational } \\
\text { Structure }\end{array}$ & $\begin{array}{l}\text { Internal } \\
\text { Systems and } \\
\text { Processes }\end{array}$ & Leadership \\
$\begin{array}{l}\text { Human Capital } \\
\text { Management }\end{array}$ & $\begin{array}{l}\text { Building Core } \\
\text { Organisational } \\
\text { Capabilities }\end{array}$ & $\begin{array}{l}\text { Creativity, } \\
\text { Innovation \& } \\
\text { Change }\end{array}$ & $\begin{array}{l}\text { Corporate } \\
\text { Identity, } \\
\text { Culture, Values, } \\
\text { Wellness }\end{array}$ \\
\hline $\begin{array}{l}\text { Customers } \\
\text { and other }\end{array}$ & $\begin{array}{l}\text { Corporate Social } \\
\text { Stakeholders }\end{array}$ & Ergonomics & $\begin{array}{l}\text { Other areas of } \\
\text { Influence }\end{array}$ \\
\hline
\end{tabular}

It was believed that industrial psychologists could prove their worth if they could demonstrate their roles and contributions in terms of each of the criteria of the criterion domain, for example: How did the industrial psychologist contribute towards ensuring the long-term sustainability of the organisation, including its relevance, growth and survival?

\section{Research approach}

A number of important perspectives were considered relevant to this study. Firstly, it was accepted that any exploratory study of this nature could never be totally objective, that no observation or description of the world can ever fully explain all there is to know, and that any scientific knowledge can only be partial at best (Willig, 2001). This position accepts that knowledge is uncertain by definition and that the best we can do is to make a stand on the basis of human judgement that requires both reason and evidence (Schwandt, 2001). Secondly, it was accepted that 'meaning' is not 'out there' but rather socially constructed (Kuhn, 2003). Social constructionism draws attention to the fact that human experience is mediated historically, culturally and linguistically (Willig, 2001). It is therefore hardly possible to imagine any universal 'truth', but rather a communal understanding and interpretation of reality at the time (Garfinkel, 2003; Gergen, 2003; Iversen, 2003; Patton, 2002; Schwandt, 2001). Social constructionists argue that 'knowing' is active (not passive) and that individuals invent concepts, models and schemes to make sense of things and continue to modify these in light of new experiences (Schwandt, 2001). This study, designed in alignment with the above-mentioned perspectives, intended to ask participating industrial psychologists to share their socially constructed meaning and individual understanding of the roles and contributions of industrial psychologists, perceived from their own reality, perspectives and context. It was hypothesised that participants' views of their profession could provide meaningful insights into the current and future value that their profession could bring to the functioning and success of organisations. It was further hypothesised that the value they bring could be made more intelligible and recognisable if it were to be delineated and described in a discourse familiar to organisations generally.

Another perspective considered relevant to the study was that of empiricism. This perspective represents the view that empirical study is valuable and useful, despite the fact that it is nowadays freely accepted that sense perception does not provide direct and uncontaminated access to 'facts' and that perception is inherently selective. Modern-day empiricists argue that knowledge acquisition still depends on data collection and analysis: "They do not believe that purely theoretical work can move us closer to the truth" (Willig, 2001, p. 4). Designing this research study such that it included an empirical component was an attempt to corroborate theoretical insights gained during earlier steps in the research process through the establishment of links with actual real-life data. The research design was specifically intended to 'test' the hypothesis that industrial psychologists can and actually do have roles to play and contributions to make in all the widely-recognised domains of organisational functioning and success identified earlier. Such an empirical validation of an earlier hypothesis sought to evaluate an idea through gathering and analysing data and through re-formulating theory as the process progresses, and for this reason this study should be regarded as tentative and subject to change along with a change of setting, of data and even of the researchers self.

It was acknowledged throughout all the stages of this study that a socially constructed concept such as any occupational or professional role could only be interpreted within a clearly defined context. It was therefore also appreciated that whatever findings were to be produced by this study had to be qualified within a specific historical, cultural and linguistic context prevailing at the time. From a social constructionist point of view it also had to be accepted that any study of this nature would necessarily deliver findings that had been influenced by the subjective interpretations of all the participants, including that of the researchers. It was nevertheless believed that the scope and scientific rigour of the research process were sufficient to counter these limitations.

A broadly qualitative research approach to the study was followed. Rossman and Rallis in Creswell (2003, p. 121) identified the following characteristics of qualitative research:

Qualitative research takes place in the natural setting. Qualitative research uses multiple methods that are interactive and humanistic. Qualitative research is emergent rather than tightly prefigured. Qualitative research is fundamentally interpretive. The qualitative researcher views social phenomena holistically. The qualitative researcher uses complex reasoning that is multifaceted. The qualitative researcher adopts and uses one or more strategies of inquiry as a guide for the procedures in the qualitative study.

Qualitative inquiry is most useful in studies where the search is for understanding, as opposed to other methods of enquiry such as observing, measuring, experimenting, drawing statistical inferences or evaluation (Hair, Babin, Money \& Samuel, 2003; Patton, 2002). Qualitative methods facilitate the study of issues in depth and detail and are especially useful as a source of grounded theory; theory that emerges from the researcher's inductive and deductive endeavours (Patton, 2002; Van der Merwe, 1996). It was believed that the research question regarding the roles and contributions of industrial psychologists 
could best be answered by a multi-faceted interpretative research approach that allowed for data from more that one source to inform understanding. This qualitative approach was chosen because it seemed appropriate in an exploratory research study where rigid and standardised research methods and processes could be prohibitive. Without knowing exactly what the roles and contributions of industrial psychologists involved, any kind of measurement or highly structured frame of thinking was perceived to limit the possibility for new insights to emerge from the study. The research question implied an inquiry about empirical reality, driven not so much by theory as by nonscientific observation (Neuendorf, 2002) and sense-making.

The qualitative research approach allowed for the gathering of information from practising industrial psychologists regarding the current and future roles and contributions of their profession in South Africa, defined and described within the multi-dimensional conceptual framework devised earlier. This approach implied a process of analytical induction through which qualitative data is sorted and interpreted within a preselected frame of reference (Esterberg, 2002; Willig, 2001). Despite the obvious restrictions of such a process in soliciting totally unstructured and free-flowing data, the approach was nevertheless followed to achieve a specific objective - that of assigning the data to an existing frame of reference that would arguably enjoy a fair degree of credibility and acceptance in the business world generally.

Considerations pertaining to reliability and validity (as these concepts apply to a qualitative research paradigm) were considered throughout. It had to be accepted that any findings based on an exploratory study of this nature - where a large degree of personal construction, uninhibited analysis of data and interpretative understanding are involved - would ultimately be subject to different perspectives and interpretation (Willig, 2001). Any findings could therefore only reflect a particular way of describing the data and would resultantly be open to re-interpretation of categories, possibly different from the interpretations and labelling arrived at by the researchers. In this respect a number of strategies were employed to enhance the trustworthiness, credibility and future usefulness of the findings. A snowball sampling strategy was employed to ensure adequate data input, interviews were spread over an extended period of time to limit random errors, and consistent data analysis procedures were followed throughout (see Esterberg, 2002). The consistency of the data analysis procedures was enhanced by the creation of systematic and comprehensive written documentation of all the analyses that informed the decision-making process. In addition, reliability was enhanced by keeping a proper audit trail and by submitting the findings for review to two other registered industrial psychologists who both have extensive experience in academic teaching, professional practice and business consulting. The face validity and credibility of the analyses and the resultant inferences were affirmed by both.

External validity (again as defined within the context of qualitative research) was enhanced by ensuring the relevance of all the characteristics pertaining to the participants, by appropriately describing all the concepts used in the study to ensure a common understanding among all participants, and by thoroughly explaining the research method (Rubin \& Rubin, 1995; Smaling in Baker, Hyland, Van Hezewijk \& Terwee, 1989). Content validity was enhanced by preparing a comprehensive register of data, by keeping field and observation notes and by regularly studying these notes to search for validation. Transferential validity was enhanced by providing an accurate description of the research process and the research situation and context (Rubin \& Rubin, 1995; Smaling in Baker et al., 1989). Overall validity was furthermore advanced by comparing emerging propositions and ideas with all parts of the existing data to check for inconsistencies or inexplicable incongruence. None of substance was found.

\section{Participants}

Participants in the study $(\mathrm{N}=25)$ were selected through a process of snowball sampling (Esterberg, 2002). This involved a deliberate effort and personal judgement to ensure an adequate sample of informants professionally registered as industrial psychologists with the Health Professions Council of South Africa. Two individuals who are not registered as industrial psychologist, but who have extensive Human Resource Management (HR) experience in executive positions were included as expert peer reviewers. A total of seventeen participants were related to universities and private consulting practices and the remainder of the sample group was employed in the private and corporate sectors. Thirteen participants had been educated in the Human Sciences, 11 in the Economic and Management Sciences and one in the Natural Sciences. The participants' average number of years of experience in the field of I/O Psychology / HR was 15, 5 years. Table 2 provides descriptive information regarding the 25 participants.

TABLE 2

DESCRIPTIVE INFORMATION OF PARTICIPANTS ( $\mathbf{N}=\mathbf{2 5}$ )

\begin{tabular}{|c|c|c|}
\hline VARIABLE & INDICATORS & NUMBER \\
\hline \multirow[t]{2}{*}{ Gender } & Male & 20 \\
\hline & Female & 5 \\
\hline \multirow[t]{4}{*}{ Race } & Black & 1 \\
\hline & Coloured & 0 \\
\hline & Indian & 0 \\
\hline & White & 24 \\
\hline \multirow[t]{8}{*}{ Occupation } & Lecturer (Industrial Psychology) & $17^{*}$ \\
\hline & I/O Psychology Consultant & $14^{*}$ \\
\hline & HR consultant & 4 \\
\hline & HR manager & 1 \\
\hline & OD manager & 1 \\
\hline & Compensation and Benefits Manager & 1 \\
\hline & Businessman & 1 \\
\hline & $\begin{array}{l}\text { * A number of full-time lecturers render } \\
\text { professional consultancy services. A } \\
\text { number of full-time professionals are } \\
\text { involved in part-time lecturing at tertiary } \\
\text { level. }\end{array}$ & \\
\hline \multirow[t]{11}{*}{ Qualifications } & BA Hons (Industrial Psychology) & 1 \\
\hline & MA (Industrial Psychology) & 4 \\
\hline & MAdmin (Industrial \& Organisational Psych) & 2 \\
\hline & MA (Clinical Psychology) & 2 \\
\hline & MSc (Psychology) & 1 \\
\hline & MCom (Industrial Psychology) & 6 \\
\hline & DAdmin & 1 \\
\hline & DPhil (Industrial Psychology) & 6 \\
\hline & DCom (Industrial Psychology) & 2 \\
\hline & * 23 of the participants are registered as & \\
\hline & Industrial Psychologists with the HPCSA & \\
\hline
\end{tabular}

\section{Procedure}

All 25 participants were telephonically invited to participate in the study and all agreed unconditionally. Individual semistructured interviews were set up with each of the participants, at a time and place convenient to both parties. At the interview participants were provided with an abstract of the research proposal and a copy of the one-page summary of the Multidimensional Conceptual Framework described above (see Table 1). Participants were given time to familiarise themselves with the framework and to clear up any uncertainties with the interviewer. A mutual sense of goodwill was established and participants spontaneously indicated their eagerness to add input to a debate that they regarded relevant and important, also from their own professional perspective. In order to adhere to the principles of good practice and abide by the University of Johannesburg's guidelines for ethical research each participant signed a consent form prior to commencement of the interview. 
Each interview started with the question: "In your opinion, what are the major current and future roles and contributions of industrial psychologists within each of the sixteen dimensions of the proposed conceptual framework presented in Table 1?"

Participants were allowed to provide unstructured input within each of the sixteen dimensions. It was not found necessary to provide or request a great deal of clarification. Every participant agreed to the digital recording of their interview which lasted between 25 and 70 minutes each.

Data analysis

As a first step, the interviews were transcribed verbatim. More than a 100 pages of text was captured. The tape-recorded interviews were listened to and the verbatim transcriptions read through a number of times in order to gain broad-based insights and a feeling for the data. In order to 'let the participant speak' key notions or ideas expressed by participants were retained in their original transcribed format and sorted into the particular dimension of the proposed conceptual framework through a process of analytical induction as described above. Each participant, on average, identified three roles or contributions per dimensions which represent an average of four meaningful key responses per transcribed page. Open codes were assigned to recurring themes that were identified on the basis of similarities, differences and relationships between notions and ideas. The data input from the two participants who are not registered industrial psychologists were carefully scrutinised for any insights of a disconfirming nature. None was found. This systematic process of thematic content analysis revealed specific industrial psychological roles and contributions within each of the sixteen dimensions. The specific industrial psychological roles within each of the sixteen dimensions are presented in Table 3 . The specific industrial psychological contributions are discussed under separate headings in the Findings section below.

\section{FINDINGS}

The findings of the study are reported in two parts, roles of I/O Psychologists and contributions of I/O Psychologists as defined within each of the dimensions of the Multi-dimensional Conceptual Framework.

\section{Roles of I/O Psychologists}

The participants made 143 references to current and future industrial psychological roles. These roles are depicted in Table 3.

From the 143 references above, thirty seven distinctive roles could be identified which were representatively distributed across all sixteen dimensions of the Multi-dimensional Conceptual Framework. The 37 different roles were reduced to six broad, generic roles: scientist/researcher, strategic partner, enabler, developer/counsellor, watchdog and leader. It was immediately clear that most of the identified roles were not exclusive to the profession of industrial psychologists and in many respects, probably just as applicable to the HR practitioner. However, a number of observations was noteworthy:

The scientist/researcher role was mentioned no less than 37 times (26\% of the responses). Participants personally viewed their input as science-based and specialised: "Scientist, researcher, diagnostician, observer, analyst, academic and investigator". The strategic partner role was highlighted as crucial to ensure acceptance and credibility for the profession and its practitioners ( $7 \%$ of the responses). The role of the industrial psychologist mentioned most frequently ( $41 \%$ of the responses) was that of an "enabler": "Advisor, consultant, facilitator, intervention role, soundboard, interdisciplinary role". The industrial psychologist was not so much framed as a "doer" in his own right but rather as someone that helps others to do. No mention whatsoever was made of an administrative or even line management role. A development/counselling role featured clearly (14\% of the responses), often as part of a mentoring or coaching relationship. The watchdog role was strongly emphasised (6\% of the responses): "Custodians of ethical values, conscience, conscience role, super-ego role, awareness creator". The role of the industrial psychologist as a leader also featured strongly (6\% of the responses): "Influencer, leader, direction-giving, change agent".

TABLE 3

ROLES OF IDUSTRIAL PSYCHOLOGIST PER DIMENSION1

\begin{tabular}{|c|c|c|c|}
\hline $\begin{array}{l}\text { Long-term } \\
\text { Sustainability } \\
\text { of the } \\
\text { Organisation }\end{array}$ & $\begin{array}{l}\text { Governance } \\
\text { and Ethics }\end{array}$ & $\begin{array}{l}\text { Financial } \\
\text { Well-Being } \\
\text { of the } \\
\text { Organisation }\end{array}$ & $\begin{array}{l}\text { Strategic } \\
\text { Positioning, } \\
\text { Vision and } \\
\text { Mission }\end{array}$ \\
\hline $\begin{array}{l}\text { - Advisor } \\
\text { - Consultant } \\
\text { - Enabler } \\
\text { - Facilitator } \\
\text { - Influencer } \\
\text { - Intervention role } \\
\text { - Marketer } \\
\text { - Researcher } \\
\text { - Scientist } \\
\text { - Soundboard } \\
\text { - Strategic partner }\end{array}$ & $\begin{array}{l}\text { - Academic } \\
\text { - Advisor } \\
\text { - Communicator } \\
\text { - Consultant } \\
\text { - Custodians of } \\
\text { ethical values } \\
\text { - Facilitator } \\
\text { - Interdisciplinary } \\
\text { role } \\
\text { - Leader } \\
\text { - Practitioner } \\
\text { - Researcher } \\
\text { - Scientist } \\
\text { - Strategic partner } \\
\text { - Watchdog }\end{array}$ & $\begin{array}{l}\text { - Advisor } \\
\text { - Awareness } \\
\text { creator } \\
\text { - Diagnostician } \\
\text { - Evaluator } \\
\text { - Facilitator } \\
\text { - Researcher }\end{array}$ & $\begin{array}{l}\text { - Advisor } \\
\text { - Coaching } \\
\text { - Development } \\
\text { - Diagnostic role } \\
\text { - Direction-giving } \\
\text { - Facilitator } \\
\text { - Influencing role } \\
\text { - Leadership role } \\
\text { - Mentoring } \\
\text { - Mothering role } \\
\text { - Researcher } \\
\text { - Scientific role } \\
\text { - Strategic partner }\end{array}$ \\
\hline Strategie & $\begin{array}{l}\text { Organisational } \\
\text { Structure }\end{array}$ & $\begin{array}{l}\text { Internal } \\
\text { Systems and } \\
\text { Processes }\end{array}$ & Leadership \\
\hline $\begin{array}{l}\text { - Coach } \\
\text { - Consulting } \\
\text { - Development } \\
\text { role } \\
\text { - Diagnostic role } \\
\text { - Facilitator } \\
\text { - Influencing role } \\
\text { - Integrating role } \\
\text { - Mentor } \\
\text { - Mothering role } \\
\text { - Strategic partner } \\
\text { - Watchdog }\end{array}$ & $\begin{array}{l}\text { - Advisor } \\
\text { - Awareness } \\
\text { creator } \\
\text { - Business partner } \\
\text { - Conscience } \\
\text { - Consultant } \\
\text { - Diagnostician } \\
\text { - Facilitation } \\
\text { - Intervention role } \\
\text { - Investigator } \\
\text { - Observer } \\
\text { - Supporting role }\end{array}$ & $\begin{array}{l}\text { - Advisor } \\
\text { - Analyst } \\
\text { - Consultant } \\
\text { - Councillor } \\
\text { - Evaluator } \\
\text { - Facilitator } \\
\text { - Mentor } \\
\text { - Researcher }\end{array}$ & $\begin{array}{l}\text { - Advisor } \\
\text { - Coaching } \\
\text { - Counselling } \\
\text { - Facilitator } \\
\text { - Guide } \\
\text { - Influencing } \\
\text { - Leadership role } \\
\text { - Mentoring } \\
\text { - Researcher } \\
\text { - Watchdog }\end{array}$ \\
\hline $\begin{array}{l}\text { Human Capital } \\
\text { Management }\end{array}$ & $\begin{array}{l}\text { Building Core } \\
\text { Organisational } \\
\text { Capabilities }\end{array}$ & $\begin{array}{l}\text { Creativity, } \\
\text { Innovation \& } \\
\text { Change }\end{array}$ & $\begin{array}{l}\text { Corporate } \\
\text { Identity, } \\
\text { Culture, } \\
\text { Values, } \\
\text { Wellness }\end{array}$ \\
\hline $\begin{array}{l}\text { - Advisor } \\
\text { - Coach } \\
\text { - Consultant } \\
\text { - Facilitator } \\
\text { - Mentor }\end{array}$ & $\begin{array}{l}\text { - Advisor } \\
\text { - Coach } \\
\text { - Consultant } \\
\text { - Diagnostician } \\
\text { - Facilitator } \\
\text { - Negotiator } \\
\text { - Observer } \\
\text { - Researcher }\end{array}$ & $\begin{array}{l}\text { - Advisor } \\
\text { - Analyst } \\
\text { - Change agent } \\
\text { - Conscience role } \\
\text { - super ego role } \\
\text { - Consultant } \\
\text { - Diagnostician } \\
\text { - Facilitation } \\
\text { - Guide } \\
\text { - Watchdog }\end{array}$ & $\begin{array}{l}\text { - Change agent } \\
\text { - Coach } \\
\text { - Consultant } \\
\text { - Diagnostic } \\
\text { - Facilitation } \\
\text { - Inter- } \\
\text { disciplinary role } \\
\text { - Mentor } \\
\text { - Observer } \\
\text { - Researcher } \\
\text { - Strategic partner }\end{array}$ \\
\hline $\begin{array}{l}\text { Customers } \\
\text { and Other } \\
\text { Stakeholders }\end{array}$ & $\begin{array}{l}\text { Social } \\
\text { Responsibility }\end{array}$ & Ergonomics & $\begin{array}{l}\text { Other areas of } \\
\text { Influence }\end{array}$ \\
\hline $\begin{array}{l}\text { - Business partner } \\
\text { - Consultant } \\
\text { - Diagnostician } \\
\text { - Facilitator } \\
\text { - Inter-disciplinary } \\
\text { role } \\
\text { - Partnership role } \\
\text { - Researcher } \\
\text { - Strategic partner } \\
\text { - Watchdog }\end{array}$ & $\begin{array}{l}\text { - Advisor } \\
\text { - Awareness } \\
\text { - Consultant } \\
\text { - Facilitator } \\
\text { - Interdisciplinary } \\
\text { role (team } \\
\text { member) } \\
\text { - Observer } \\
\text { - Researcher } \\
\text { - Super-ego of org }\end{array}$ & $\begin{array}{l}\text { - Advisor } \\
\text { - Consultant } \\
\text { - Researcher } \\
\text { - Specialised role } \\
\text { - Team role } \\
\text { with inter- } \\
\text { disciplinary } \\
\text { team }\end{array}$ & $\begin{array}{l}\text { - Advisor } \\
\text { - Business partner } \\
\text { - Expert witness } \\
\text { - Facilitator } \\
\text { - Forensic } \\
\text { industrial } \\
\text { psychology } \\
\text { - Influencing role } \\
\text { - Leadership role }\end{array}$ \\
\hline
\end{tabular}




\section{Contributions of I/O Psychologists}

The participants identified the following contributions by industrial psychologists, again within each of the sixteen dimensions of the conceptual framework.

\section{Dimension 1: Long-term sustainability of the organisation} Specific contributions were highlighted within this dimension. One participant made it particularly clear: "I think there are few people who are so well positioned to realise this strategic partnership than industrial psychologists who understand business". Specific reference was made to the industrial psychologist's role in "looking and interpreting the organisation's long term needs in terms of its people requirements". Possible future contributions included the development of utility models that would enable practitioners to highlight the rand-and-cent value added by industrial psychologists and their interventions. This notion was supported by statements such as: "Something that is important today is utility analysis, that is, to justify your contributions in terms of rand-and-cent value" and "[a] facet which is coming through strongly, but perhaps neglected whether due to ignorance or not, is that of utility models, the role he (the industrial psychologist) will play in the validation of instruments and also to spell out the financial implications for the use of selection instruments, what are the rand-and-cent impact on the organisation". Throughout the notion of a need for involvement at higher organisational levels was stressed.

\section{Dimension 2: Governance and ethics}

Many contributions were highlighted in this domain although most participants focused on ethics rather than on governance. In terms of governance it was stated that industrial psychologists should "help with the design of organisational governance models". In terms of ethics the contribution was made very clear: "The promotion of ethics within organisations" and also "I think we much teach people what work ethics is, it is an educational task" and "because we work with ethical issues on a daily basis, industrial psychologists should become the custodians of ethical values within organisations and thereby helping to establish a culture of ethics". It was also suggested that industrial psychologists should act as the ethical watchdogs of the organisation, with statements such as: "Watchdog in the good sense of the word, to clarify perceptions and to carry over information" and "[a]n industrial psychologist should be like a watchdog, an ethical watchdog". A future contribution included how ethics will be defined in future: "The industrial psychologist should explore the nature of ethics in the new world of work".

\section{Dimension 3: Financial well-being of the organisation}

Every participant highlighted contributions within this dimension. One of the contributions was seen to be the development of human potential and talent in order to contribute to the financial well-being of the organisation. One participant worded it such: "I think this is where we can make a contribution, it is an indirect contribution to ensure that the money is well invested". This notion was supported by another who stated: "Investing in people by creating the conditions that will allow them to thrive in the organisation" and that industrial psychologists should "continuously take account of and measuring the impact of human capital costs in terms of the overall financial picture of the organisation". In terms of possible future contributions the need for the development of utility models to indicate the relative financial value of industrial psychology interventions and actions was reiterated: "Industrial psychologists must develop much stronger utility models in terms of the value they add". This notion was supplemented by the following statement: "Industrial psychologists should engage in awareness making campaigns in terms of the financial implication of industrial psychology actions and interventions".

Dimension 4: Strategic positioning, vision and mission

Playing a facilitation and advisory role in the development of the organisation's mission and vision were reported by many of the participants. Statements in support of this comment included: "Yes, I think they can contribute in an advisory capacity with the formulation of missions, visions and values since it is rooted in the human behaviour aspects" and "I think that the industrial psychologist has a facilitating role to play in respect of the formulation of the strategic position of the organisation". A further contribution related to "assisting in creating the conditions for employees to effectively contribute towards the organisation's vision". The development and empowerment of people in order to achieve the organisation's vision was also suggested with statements such as: "Industrial psychologists must engage in competency profiling which supports the organisation's strategic position, vision and mission", and "the development of people development strategies to ensure a healthy organisation". Possible future contributions were to move beyond being a strategic partner towards becoming a strategic leader in the organisation: "[t]he latest indication is that he (the industrial psychologist) should be directive, a leader and not only a partner, in terms of soft issues."

\section{Dimension 5: Strategies}

Many contributions were identified in this dimension. One of the contributions reported was that of "aligning human capital management strategies with organisational strategies". This notion was supported by another statement: "Industrial psychologists have an input on how to get people on board and how to motivate people to operate within the new world of work". Another contribution was that of facilitating the rolling out (translating) of strategies down to the lowest level of the organisation. This was to be achieved by "...facilitating the translation of competencies into strategies. Industrial psychologists are supposed to understand how values, interests, personality and motivation are related to performance in the workplace". Another contribution related to the development and implementation of wellness strategies, including aspects such as the "promotion of health", "psychology development programmes" and "stress management". Two possible future contributions referred to strategies aimed at the retention of personnel, wellness and more specifically on how to proactively keep people in the organisation healthy. One participant stated:

I think there are wonderful HR strategies already in place. But strategies which are not addressed adequately are things such as the retaining of personnel. What is our strategy? How will we retain our personnel? And another strategy that goes handin-hand with this is individual and organisational wellness. There is really a shortage of strategies and policies in terms of individual and organisational wellness. I do not think that it is addressed on a strategic level. For me it is reactive, we only do crises management. Many companies do trauma work, for example. It is managed as the trauma arises, but without proactive thinking in this regard. How do we ensure our people's wellness? We cannot only be reactive in this regard. So I believe that there are not enough proactive HR policies... I think our frame of reference needs to be shifted towards more proactive thinking in this regard in order to ensure the wellness of our people. I mean psychology is moving towards positive psychology and we must go with the flow. The new psychology paradigm is positive psychology. The whole idea of positive psychology is not really being used in organisations. It is regarded as a nice idea and a popular concept.

\section{Dimension 6: Organisational structure}

It was stated more than once that organisational structures are not a pure $\mathrm{I} / 0$ Psychology function and that industrial psychologists mainly render an advisory function in this regard in order to "create the best and most effective structures". Industrial psychologists are also involved in determining the "impact of organisational structure on the culture... to see how the current structure has an influence on performance and if the structure is conducive for good performance". It was also mentioned that the concept of organisational structures is becoming obsolete in the new world of work: "Organisational structures are becoming a misnomer and it will be more so in 
future where the focus will be on relationships rather than formal structures". A possible future contribution is that of working with structures on a meta-level:

My hypothesis is that an organisation contains its anxiety in things such as job descriptions and organisational structures ... don't get bogged down with the figure (organogram) on the wall and say that that is the organisation ... the structure is the mechanics and that what happens in the organisation...the dynamics.

\section{Dimension 7: Internal systems and processes}

A number of contributions were identified in this dimension. Apart from the traditional contributions such as performance management, employee assistance programmes, and matching and alignment of systems and processes within the organisation, participants highlighted their involvement and contributions in the more psychological parts of systems and processes, for example: "Monitoring the (psychological) impact of systems in the organisation" and "The industrial psychologist must work with the dynamics and not the mechanistic matters". A possible future contribution was described as follows: "The industrial psychologist should have more to do with the things below the surface and the HR practitioner the daily management of the human resources functions." Also, industrial psychologists should be working with systems and processes on a meta-level, "ensuring the implementation of systems and processes on a psychological level within the organisation".

\section{Dimension 8: Leadership}

Contributions within this dimension were regarded as very important. The identification and development of leadership were two contributions reported by almost everyone. In this regard the "the identification of leadership potential and the subsequent development thereof" and "the development of leadership development interventions" were perceived as crucially important. One participant worded it as follows:

[t]hroughout the years I/O Psychology stood strong on the area of leadership in organisations. It is still regarded as one of the main domains of their involvement. Students of I/O Psychology spent a lot of time on leadership development. Therefore, I think, they can still render an important contribution towards the development of leadership in organisations.

Coaching and mentoring contributions in terms of leadership were mentioned often, with one participant stating:

I think there is an ever-increasing demand for leadership development. Just look at how many people are registering themselves as executive coaches. There is development taking place in that field which is quite scary. I do not know how well they are conversant with regard to leadership theory and development, because if you do not understand it, it can be quite difficult to do executive coaching; that on the one side, and leadership development together with career development. You know career psychology is lectured everywhere, but I don't think that industrial psychologists practice it as such within organisations. How do you really provide constructive assistance to people in career planning? And how do you develop leadership? I think, especially in this country, that our leadership issues are huge. Young people enter leadership positions without being ready for it. To this end the industrial psychologist has a phenomenal role to play. There is a huge requirement out there in coaching and mentoring.

A further possible future contribution was that of developing emotional intelligence in people: "The whole new concept of emotional intelligence to show leaders what is their own leadership role, how people view them, how they view themselves and how they operate in their environment."

\section{Dimension 9: Human capital management}

Contributions in this dimension revolved mainly around the identification and development of human resources, particularly talent management at a 'meta-level'. Many participants reported that human capital management is probably one of the industrial psychologist's greatest contributions: "Yes, definitely, a very, very important role. I would say that it is probably one of the greatest roles we have...since people is our greatest resource and most important resource". One participant identified the contribution clearly:

Most important role. It includes the building of commitment and scope to attain both organisational and personal aspirations and needs. It would probably include most of the existing HR practices, but it would however focus far more strongly on building the psychosocial contract between the different stakeholders".

The concept of wellness also surfaced: "It includes the wellness of people, but also the capacity building of people, and the measurement of any intervention programme and the management of change".

Dimension 10: Building core organisational capabilities Contributions that were highlighted included the selection of people to promote the organisation's core business, the identification of core competencies and the development of core competencies: "It deals with the sourcing and retaining of competence and capital" and "continuous learning and continuous development". It also involves the translation of core capabilities into behaviour: "There is certainly a role to help with the identification of the core organisational capabilities, but I think the greater role is to take capabilities and to translate it into behaviour in order to create a language which the organisation can use in order to realise the core capabilities." The future role of building organisational capabilities was described by one participant by means of an analogy:

I am of the opinion that the role of the industrial psychologist is becoming more and more the definition of the MS Windows which make other applications work. So where we initially focussed on selection, on $O D$, on training, etc. almost as independent applications, it is important that the industrial psychologist defines a language, platform just like Windows, a language which allows you to cut and paste in PowerPoint or in Word, where you should be able to 'paste' the measurement you obtained in the selection model into a training model, and that language is the domain of the industrial psychologist.

Dimension 11: Creativity, innovation and change

Contributions such as the facilitation of creativity, innovation and change as well as breaking down resistance to change, were identified with comments such as: "It is the role of the industrial psychologist to optimise creativity, innovation and change in organisations" and "We should provide guidance to line management on how to initiate and manage the processes and to keep the people excited in this regard." Another contribution is that of facilitating the establishment of a culture conducive to creativity, innovation and change:

How do we think about creativity, innovation and change? And how do we translate it in organisations? Is it something that is threatening which must be stopped or is it something that must be embraced? The 'mindset' of the organisation will play a huge role in this regard...and this is what the industrial psychologist should be busy with."

The contributions in terms of this dimension leans toward the building of the internal capacity to be creative, establishing a culture of creativity, innovation and change. Creating a supportive context was also highlighted as an important area of influence: "This is probably an area where industrial psychologists can play a major role, due to the fact that organisations change so fast and sometimes without taking into consideration the impact of change."

Dimension 12: Corporate identity, culture, values and wellness Many important contributions were highlighted in this dimension such as the identification of the above, and the development of models and programmes to promote the establishment and maintenance thereof: "Industrial psychologists have a role to 
play in the establishment of culture, and the establishment and identification of value systems" while another reported that "You should be able to challenge systems, question the culture and be able to say what is right and what is wrong." The future role was foreseen: "A far greater contribution not just in terms of the human resources of the organisation, but in terms of the organisation as an entity within the broader society; therefore, building organisational wellness, beyond employee wellness." Other areas highlighted by the participants included aspects such as "positive psychology", the use of "appreciative inquiry" and the development of "organisational virtues".

\section{Dimension 13: Customers and stakeholders}

Participants highlighted important contributions within this dimension such as research as well as the training and education of all the role-players to achieve customer satisfaction, both internal and external. One participant stated:

I think customers and stakeholders will also link up with aspects such as profitability and financial well-being of the organisation, in the end this is what it is all about...so I think industrial psychologists must do more research to test various interventions in various scenarios such as call-centres instead of the traditional client service approach.

From the responses it also became clear that the definition of customers and stakeholders was expanding to include both internal and external clients and stakeholders, such as "employees, families of employees and immediate surrounding communities." Consumer psychology in particular was viewed as a field that would probably become a "specialised field looking at amongst other things client satisfaction strategies, consumer behaviour, etc."

Two possible future contributions were highlighted. One was an expansion of the traditional role of the industrial psychologist in terms of customers and stakeholders:

In the past we talked about being client focused and that you render a certain service to them, but I see the role of the industrial psychologist in this regard more as a business partner. In other words, you must firstly understand their business in the milieu within which they operate and to support them in terms of their business. Proactive support to your business partner.

The second referred to a more meaningful contribution in terms of the systems psycho-dynamics model approach:

It goes about human relationships, how they are managed. In this regard I want to refer to the systems psycho-dynamics model. It is almost "Freud in the organisation" or a Tavistock approach, which states that behaviour in an organisation is conscious but mostly subconscious. And how can we tap into the manifestation of behaviour in order to see what happens on the subconscious level?

\section{Dimension 14: Social responsibility}

Many contributions were highlighted within this dimension. The reported involvement ranged from internal contributions such as wellness programmes, black empowerment and gender empowerment to external contributions by reaching out to the immediate surrounding communities. One participant stated: "I think that industrial psychologists were traditionally quite involved with social responsibility and that, in future, it will become an even more important component of the organisation, especially in terms of the wellness of employees as well as the immediate surrounding communities." To this end, the reported contribution covers aspects such as facilitating, awarenessmaking and education of social responsibility in its broadest sense within organisations. A possible future contribution would be for industrial psychologists to "become the super-ego of the organisation" in terms of social responsibility.

Dimension 15: Ergonomics

In terms of current contributions in the area of Ergonomics participants reported both supporting and non-supporting statements about whether Ergonomics still belongs to the field of I/O Psychology or not. Supporting statements of those opposed to Ergonomics belonging to I/O Psychology were: "I feel that it is not the domain of the industrial psychologist. I feel that it is the domain of the engineering field"; "I see that engineers should take over this responsibility" and "I do not really see a role unless a person is truly specialised in the field". On the other hand, statements which supported the notion that industrial psychologists can still make valuable ergonomics contributions included the following:

I think it should still be valid, especially in light of technology that changes. New technology in the mining industry, for example, is important to be studied in terms of its impact. And I do not refer only to those traditional medical aspects, which is quite familiar to us, such as back pain, but also stress, concentration and those types of things.

Another supportive statement placed emphasis on the 'psychological' aspects of Ergonomics: "The contributions of industrial psychologists in terms of ergonomics faded with time; I still think that they can render an important contribution especially in terms of the psychological component of ergonomics which is still regarded as one of its main components. The psychology of the worker."

\section{Dimension 16: General (other areas of influence)}

Three areas of influence not covered under any of the other dimensions were mentioned: Research, forensics, and being a psychologist vs. HR practitioner. One participant was of the opinion that the role of the industrial psychologist as researcher and creator of knowledge should feature far more strongly; "should read more and learn more and publish more practical and more understandable research material, using the self as instrument of evaluation." Another participant mentioned a possible forensics role: "The role of the industrial psychologist in the forensic world, in the legal environment and the law. The identification and qualification of claims, labour relations, disputes and acting as an expert witness." A third participant referred to the overall role of the industrial psychologist as a psychologist:

I do think that industrial psychologists became more and more involved in pure HR aspects with the psychology aspects left behind, although it is somewhat integrated, but I think in terms of future identity and identification, industrial psychologist should re-look at, for example, better generic training in which industrial psychologists are exposed to (in terms of) aspects such as employee health and wellness etc. Many industrial psychologists became nothing more than consultants and true I/O Psychology inputs were sacrificed for the sake of HR consultation.

\section{DISCUSSION}

The fact that such as wide array of roles and contributions were identified within each of the sixteen dimensions of the conceptual framework, served to partially validate the usefulness of the framework to define the roles and contributions of industrial psychologists in a discourse generally familiar to business. It demonstrated that industrial psychologist have meaningful roles to play and contributions to make in all the dimensions of business perceived to be important, according to three popular business management frameworks used as a basis for this study (Balanced Scorecard, South African Excellence Model, King II Report on Corporate Governance for South Africa). It is consequently argued that the contribution of the industrial psychologist is likely to be appreciated more if its value is defined in accepted business-world discourse, broadly referring to concepts such as: Long-term sustainability, financial well-being, strategic positioning, customers and other stakeholders. At the same time it is argued that it is up to the industrial psychologist to make others within the business world more 
aware of generally accepted industrial psychological discourse and concepts such as: Talent management, organisational identity, organisational values and organisational wellness.

The nature of the suggested wide-spread involvement of the industrial psychologist implied involvement at the highest levels of discussion and decision-making in the organisation. All six generic roles of the industrial psychologist identified by the participants in the study (scientist/researcher, strategic partner, enabler, developer/counsellor, watchdog and leader) suggested a scope of influence beyond the boundaries of any particular line function (specifically $\mathrm{HR}$ in this respect). It was especially noteworthy that so little mention was made of the industrial psychologist's role as an HR practitioner in terms of traditional HR functions such as recruitment, selection, performance management, compensation and collective bargaining. Significantly more emphasis was placed on intangible value-adding inputs, such as acting as "facilitator, consultant, soundboard, interdisciplinary team member, super-ego of the organisation, conscience, watchdog, leader and guide".

The current organisational utilisation and involvement of many of the participants in the study did, however, not reflect the abovementioned roles and contributions with any degree of clarity. Many of the participants made it very clear that their current input within their organisations was not primarily industrial psychological in nature and many were adamant that their roles and contributions were severely restricted by their positions as traditional HR practitioners. This phenomenon was widely attributed to the fact that very few organisations establish positions for dedicated and specialised industrial psychologists and rather employ these professionals as HR practitioners or consultants. Most of the participants expressed their serious discontent with their excessive involvement with more traditional tactical HR functions, but acknowledged that they found themselves in a precarious position since they were formally employed as HR practitioners or consultants. Although none of the participants found themselves in organisational change or organisational development positions, some did report that their organisations often make use of specialised categories of professionals, including industrial psychologist on an outsourced basis, for this purpose.

The above reality reaffirmed the need for continued debate regarding the differentiation of roles and contributions of industrial psychologists and HR practitioners. It also emphasised the need to create greater awareness among organisational decision-makers as to the value that industrial psychologists can add to their organisational sustainability, success and overall wellness. A number of further research questions emerged at this point:

1. Does the academic teaching of industrial psychologists and HR practitioners define the practice domain of each of the two study fields with a sufficient degree of clarity? A superficial overview of the BCom curricula at seven reputable South African universities showed little differentiation between the curricula of the two study fields, and often the two fields of study were fully integrated. This immediately raised doubts whether practitioners themselves have adequate role clarity.

2. It is often argued that true 'value' is defined by the receiver and not by the giver. Although industrial psychologists strongly believed that their contributions are valuable, it can be asked whether this value does not become relevant only if the receivers of the industrial psychological services and inputs (that is organisations, managers, individuals) perceive the value as such. This presents a revolving question in that it can probably be asked if the curricula of I/O Psychology and HR were fused because of industry's demands for an 'integrated' profession or whether industry's application and use of the two professions became blurred as a result of the apparent fusion and overlap of the respective academic routes. Do organisations in fact require the services of HR practitioners more than they require the services of industrial psychologists or did academic institutions steer organisations towards this fusion by fusing the curricula of I/O Psychology and HR? In other words, did the distinction between $\mathrm{I} / \mathrm{O}$ Psychology and HR only became faded, as Schreuder (2001) suggested, when departments of certain universities changed the name and field of I/O Psychology initially to Personnel Management and later to Human Resources Management? Either way, it appears as if the fusion resulted in a potential diminishing of the level at which industrial psychologists could make a contribution, especially if they find themselves in HR positions.

3. Whilst it can obviously be argued that it is only a matter of creating greater awareness, the question does arise whether this might not require, as a prerequisite, much stronger evidence to validate the actual 'objectively measured' value that industrial psychologists can add. Is it enough for industrial psychologists to believe that they have value to add?

4. Lastly, while the participants in the study expressed strong beliefs about their current and future roles and contributions, one does wonder whether they are in fact adequately trained for this purpose. Do I/O Psychology curricula address the educational, training, developmental and skills needs of psychologists, if these were to be measured against the proposed Multi-dimensional Conceptual Framework? Appropriate knowledge, skills and competence to act as change agents, counsellors, leadership coaches, ethics 'watchdogs' and corporate governance leaders, for example, come to mind.

The findings of this study regarding the roles and contributions of industrial psychologists in the South African context should be regarded as tentative because the credibility and overall validity of a study of this nature is always limited to an extent. In the first place it should be noted that both authors are registered industrial psychologists who also found themselves in HR positions for an appreciable amount of time. Total objectivity can therefore hardly be expected. Within a qualitative research approach, however, subjective closeness to the topic in this instance was not perceived as an absolute barrier, but rather as a valuable sensitivity and calculated subjectivity that may have enhanced the credibility and meaningfulness of the inferences. In the second place, it can be argued that currently registered industrial psychologists are not the only stakeholders that need to be involved in the definition and conceptualisation of the roles and responsibilities of the industrial psychologist. Users of their services (organisations, managers, individuals) and other professionals (HR practitioners, for example) may also have valuable insights to add. It is therefore suggested that a further attempt be made to gather insightful data from others, inside and outside the academic and professional fields of $\mathrm{I} / \mathrm{O}$ Psychology.

Despite the above-mentioned limitations, the study produced valuable and useful insights. It partially confirmed the usefulness of the proposed Multi-dimensional Conceptual Framework to define and describe the value of industrial psychological roles and contributions in generally understood business world language. It thus provided a framework for further systematic exploration of the specific roles and contributions of industrial psychologists within each of the sixteen dimensions. It furthermore identified and assigned a wide range of roles and contributions to industrial psychologists that cannot unconditionally be made applicable to other professionals or practitioners (for example: roles and contributions related to counselling, fostering of creativity, maintaining organisational wellness, ergonomics and consumer psychology). Whilst the study served to confirm the vast domain of (possible) influence of the industrial psychologist, it also confirmed the need to define this influence far more clearly and unambiguously. It is hoped therefore that the following recommendations will serve to stimulate debate among industrial psychologists occupied in the private, corporate, consulting and academic environment in an endeavour to bring clarity and enhanced credibility to a profession that seemingly have much to offer. The following recommendations follow from this study:

1. That the proposed Multi-dimensional Conceptual Framework be used as a basis for debate among industrial psychologists 
and other stakeholders (organisations, managers, individuals, other professionals) to more clearly define and describe the current and future value-adding roles and contributions of industrial psychologists, and that these be embodied in clear and unambiguous professional guidelines.

2. That the proposed Multi-dimensional Conceptual Framework also be used as a basis for the revision and re-alignment of the curricula for I/O Psychology teaching at South African academic institutions, with the specific purpose to establish a clear focus on the unique and specialised roles and contributions of industrial psychologists. Existing and new domains of knowledge might need to be explored in greater depth, for example: Governance and ethics, holistic wellness (positive psychology), consumer psychology, the psychological aspects of ergonomics, stakeholder theory, social psychology, the notion of social responsibility, and totally new fields such as forensic industrial psychological applications. In addition, special effort should be made to embody the scientistpractitioner nature of the profession through formal teaching, especially since it was so strongly emphasised as a competitive professional advantage.

3. That these renewed insights be used as a basis for professional industrial psychological bodies to actively promote awareness among possible users of their services regarding the value that can be derived from professional industrial psychological input, especially as this may be different from that of more traditional HR practice.

If anything, the above discussion underpins the need for further endeavours to clarify the roles and contributions of industrial psychologists in South Africa in a visionary and creative manner.

\section{REFERENCES}

Augustyn, J. C. (1982). Bedryfsielkunde in die tagtigerjare: ' $n$ Histories-fundamentele beskouing. Johannesburg: Randse Afrikaanse Universiteit. Nr. A141 van Publikasiereeks.

Baker, W. J., Hyland, M.E., Van Hezewijk, R. \& Terwee, S. (Eds.). (1989). Recent trends in theoretical psychology, Vol. 2. New York: Springer-Verlag.

Barnard, G. \& Fourie, L. (2007). A conceptual framework to explore the roles and contributions of industrial psychologists in South Africa. Journal of Industrial Psychology (In press).

Creswell, J. W. (2003). Research design: Qualitative, quantitative and mixed methods ( $2^{\text {nd }}$ ed.). California: Sage.

Esterberg, K. G. (2002). Qualitative methods in social research. Boston: McGraw Hill.

Garfinkel, H. (2003). Socially negotiating knowledge. In M. Gergen \& K. J. Gergen (Eds.). Social constructionism: A reader. London: Sage.

Gergen, M. \& Gergen, K. J. (2003). Social constructionism: A reader. London: Sage.

Grobler, P. A., W rnich, S., Carrell, M. R., Elbert, N. F. \& Hatfield, R. D. (2002). Human Resource Management ( $2^{\text {nd }}$ ed.). London: Thomson.

Hair, J. F. (Jr.), Babin, B., Money, A. H. \& Samuel, P. (2003). Essentials in business research methods. Hoboken, NJ: Wiley.
Institute of Directors (2002). King II Report on Corporate Governance for South Africa. Johannesburg: Institute of Directors.

Iversen, G. R. (2003). Knowledge as a numbers game. In M. Gergen \& K. J. Gergen (Eds). Social constructionism: A reader. London: Sage.

Kaplan, R. S. \& Norton, D. P. (1996). The balanced scorecard: Translating strategy into action. Boston: HBS.

Kuhn, T. S. (2003). On scientific paradigms. In M. Gergen \& K. J. Gergen (Eds). Social constructionism: A reader. London: Sage.

Moalusi, K. P. (2001). Industrial psychology for the creation of new futures in turbulent times. Journal of Industrial Psychology, 27(4), 17-21.

Muchinsky, P. M. (2000). Psychology applied to work. Belmont, CA: Wordsworth.

Muchinsky, P. M. (2003). Psychology applied to work (7th ed.). Belmont, CA: Wadsworth/Thomson.

Muchinsky, P. M., Kriek, H. J. \& Schreuder, A. M. G. (2005). Personnel Psychology ( $3^{\text {rd }}$ ed.). Cape Town: Oxford University Press.

Neuendorf, K. A. (2002). The content analysis guidebook. Thousand Oaks, CA: Sage.

Patton, M. Q. (2002). Qualitative research and evaluation methods ( $3^{\text {rd }}$ ed.). Thousand Oaks, CA: Sage.

Pienaar, Y. \& Roodt, G. (2001). Die teenswoordige en toekomstige rolle van Bedryfsielkundiges in Suid-Afrika. Journal of Industrial Psychology, 27(4), 25-33.

Rubin, H. J. \& Rubin, I. S. (1995). Qualitative interviewing: The art of hearing data. London: Sage.

Schreuder, A. M. G. (1999). Die ontwikkeling van Bedryfsielkunde aan Suid-Afrikaanse universiteite: ' $n$ Historiese oorsig en toekomsperspektief. Pretoria: UNISA.

Schreuder, A. M. G. (2001). The development of Industrial Psychology at South African universities: A historical overview and future perspective. Journal of Industrial Psychology, 27(4), 2-7.

Schwandt, T. A. (2001). Dictionary of qualitative inquiry ( $2^{\text {nd }}$ ed.). Thousand Oaks, CA: Sage.

Scott, W. G., Mitchell, T. R. \& Birnbaum P. H. (1981). Organizational theory: A structural and behavioural analysis. Homewood, IL: Richard D. Irwin.

South African Excellence Foundation (1997). The South African Excellence Model. Unpublished training manual.

Van der Merwe, H. (1996). The research process: Problem statement and research design. In J. Garbers (Ed.). Effective research in the social sciences. Pretoria: Van Schaik.

Veldsman, T. H. (2001). A new playing field, game and/or different rules? Into the future with Industrial Psychology as a discipline and profession. Journal of Industrial Psychology, 27(4), 34-41.

Venter, A. \& Barkhuizen, N. (2005). Rethinking undergraduate curricula: A Delphi study of Human Resource Management and Industrial and Organisational Psychology. Journal of Industrial Psychology, 31(3), 46-53.

Watkins, M. L. (2001). Industrial Psychology: An identity crisis and future direction. Journal of Industrial Psychology, 27(4), 8-13.

Westen, D. (1998). Psychology: Mind, brain \& culture ( $2^{\text {nd }}$ ed.). New York: Wiley \& Sons.

Willig, C. (2001). Introducing qualitative research in psychology: Adventures in theory and method. Buckingham, PA: Open University Press. 